\title{
Perfil de ácidos graxos no Longissimus dorsi de cordeiros Santa Inês alimentados com diferentes níveis energéticos
}

\section{Fatty acids profile in Longissimus dorsi of Santa Ines lambs fed with different energy levels}

\author{
Paulo César Lopes de Arruda ${ }^{1}$; Elzânia Sales Pereira ${ }^{2 *}$ \\ Patrícia Guimarães Pimentel; ; Marco Aurélio Delmondes Bomfim4; \\ Ivone Yurika Mizubuti5; Edson Luis de Azambuja Ribeiro; \\ Rildson Melo Fontenele ${ }^{6}$; José Gilson Louzada Regadas Filho ${ }^{7}$
}

\section{Resumo}

O presente estudo objetivou avaliar a influência de rações com diferentes níveis de energia metabolizável sobre o teor de lipídeos totais, colesterol e perfil de ácidos graxos no músculo Longissimus dorsi de cordeiros Santa Inês. Foram utilizados 20 cordeiros, com idade e peso de 50 dias e 13,0 $\pm 0,56 \mathrm{~kg}$, respectivamente, alimentados com rações contendo diferentes níveis energéticos: 2,08; 2,28; 2,47 e $2,69 \mathrm{Mcal} / \mathrm{kgMS}$. Os animais foram pesados semanalmente para acompanhamento do ganho de peso vivo, quando a média do peso vivo do tratamento atingiu $28 \mathrm{~kg}$, os animais foram abatidos. A análise do perfil lipídico do músculo Longissimus dorsi apresentou efeito linear crescente e decrescente para os ácidos Cis-10 heptadecanóico (C17:1) e eicosatrienóico (C20:3), respectivamente, com o aumento nos níveis de energia dietéticos $(\mathrm{P}<0,05)$. Os níveis de colesterol $(\mathrm{mg} / 100 \mathrm{~g})$ decresceram em relação ao aumento nos níveis de energia das rações. As relações ácidos graxos poliinsaturados (AGPI):ácidos graxos saturados (AGS); AGPI:ácidos graxos monoinsaturados (AGM); AGM:AGS; ácidos graxos desejáveis, $\omega-6: \omega-3$, índice de aterogenicidade, índice de trombogenicidade, relação entre os ácidos graxos hipercolesterolêmicos e hipocolesterolêmicos e a relação $(\mathrm{C} 18: 0+\mathrm{C} 18: 1)$ :C16:0 não foram influenciadas pelos níveis energéticos $(\mathrm{P}>0,05)$. A manipulação dietética influencia o perfil lipídico no Longissimus dorsi de cordeiros Santa Inês.

Palavras-chave: Ácidos graxos insaturados, carne de cordeiro, índice de aterogenicidade

\footnotetext{
Abstract

This study evaluated the influence of rations with different levels of metabolizable energy on the content of total lipids, cholesterol and fatty acid profile of the longissimus dorsi of Santa Ines lambs. Twenty Santa Ines lambs were used, with age and body weight of 50 days and $13.0 \pm 0.56 \mathrm{~kg}$, respectively, fed rations with different energy levels: $2.08 ; 2.28 ; 2.47$ e $2.69 \mathrm{Mcal} / \mathrm{kgDM}$. Animals were weighed weekly

${ }^{1}$ Doutorando do Programa de Pós-Graduação em Zootecnia da Universidade Federal do Ceará, UFC, Fortaleza, CE. E-mail: pcesarr@hotmail.com

2 Prof ${ }^{a}$ do Dept $^{\circ}$ de Zootecnia da UFC, Fortaleza, CE. Bolsista de produtividade do CNPq. E-mail: elzania@hotmail.com

${ }^{3}$ Prof $^{\mathrm{a}}$ do Dept ${ }^{\mathrm{o}}$ de Zootecnia da UFC, Fortaleza, CE. E-mail: pgpimentel@hotmail.com

${ }^{4}$ Pesquisador Empresa Brasileira de Pesquisa Agropecuária, Centro Nacional de Pesquisa de Caprinos, Sobral, CE. E-mail: mabomfim@cnpc.embrapa.br

5 Profs. Drs. do Dept ${ }^{\circ}$ de Zootecnia. Universidade Estadual de Londrina, UEL, Londrina, PR. Bolsista de Produtividade do CNPq. E-mail: mizubuti@uel.br; elar@uel.br

${ }^{6}$ Doutorando do Programa de Pós-Graduação em Zootecnia da, UFC, Fortaleza, CE. E-mail: rildsonfontenele@gmail.com

${ }^{7}$ Doutorando do Dept $^{\circ}$ de Zootecnia da Universidade Federal de Viçosa, UFV, Viçosa, MG. E-mail: gilsonagro@yahoo.com.br

* Autor para correspondência
} 
to follow their body weight gain (BWG); when the mean BW of the treatment reached $28 \mathrm{~kg}$, the animals were slaughtered. The analysis of the lipid profile of Longissimus dorsi presented linear increasing and decreasing for the Cis-10 heptadecanoic acid (C17:1) and eicosatrienoic (C20:3), respectively, with the increasing dietary energy levels $(\mathrm{P}<0.05)$. Cholesterol levels $(\mathrm{mg} / 100 \mathrm{~g})$ decreased in relation to the increase in energy levels in the diet. The relations polyunsaturated fatty acids (PUFA): saturated fatty acids (SFA); PUFA: monounsaturated fatty acids (MUA), MUA: SFA, desirable fatty acids, $\omega-6: \omega-3$, atherogenicity index, thrombogenicity index, relation between hypocholesterolemic and hypercholesterolemic fatty acids and the relation $(\mathrm{C} 18: 0+\mathrm{C} 18: 1): \mathrm{C} 16: 0$ were not affected by energy levels $(\mathrm{P}>0.05)$. The dietary manipulation influences the lipid profile in Longissimus dorsi of Santa Ines lambs.

Key words: Atherogenicity index, lamb meat, unsaturated fatty acids

\section{Introdução}

Rações de ruminantes são constituídas, principalmente, por ácidos graxos insaturados, os quais são quase em sua totalidade hidrogenados pelas bactérias do rúmen. O processo de biohidrogenação é de suma importância, pois além de diminuir a concentração de lipídeos insaturados, os quais são tóxicos aos microrganismos, contribuem para a retirada de íons $\mathrm{H}^{+}$do ambiente ruminal, evitando seu acúmulo. O processo de biohidrogenação ainda confere uma peculiaridade aos ruminantes, que é a composição da gordura corporal diferente da dietética, uma vez que a hidrogenação dos ácidos graxos insaturados tem como principal produto o ácido esteárico (BANSKALIEVA; SAHLU; GOETSCH, 2000; FRENCH et al., 2000). Entretanto, em algumas condições dietéticas, o processo de biohidrogenação não se completa, permitindo a produção e a absorção pelo animal dos intermediários deste processo. Estratégias nutricionais têm sido utilizadas para modificar o conteúdo e as concentrações dos diferentes ácidos graxos na musculatura animal (ANDRAE et al., 2001).

O crescente interesse por parte da população humana em consumir alimentos saudáveis e, em alguns casos, com propriedades funcionais benéficas à saúde humana tem promovido mudanças nos hábitos alimentares. As carnes de melhor qualidade nutricional e sensorial passaram a ser preferência, sendo essa geralmente explicada pela quantidade de gordura presente e pela composição dos ácidos graxos. Existe uma correlação positiva entre o consumo de gorduras de origem animal e doenças coronárias, refletindo na exigência cada vez maior de produtos de origem animal com baixos teores de colesterol e maiores percentuais de ácidos graxos insaturados e poliinsaturados (PARODI, 1999).

A avaliação da qualidade nutricional de lipídeos em carcaças de ruminantes tem sido realizada com base na composição de ácidos graxos, por meio da determinação de índices que relacionam o conteúdo de ácidos graxos saturados (AGS), monoinsaturados (AGM) e poliinsaturados (AGPI) séries $\omega-6$ e $\omega-3$. As razões AGPI: AGS e $\omega-6: \omega-3$ têm sido utilizadas com frequência para análise do valor nutricional de óleos e gorduras e indicar o potencial colesterolêmico. Índices de aterogenicidade (IA) e trombogenicidade (IT) são utilizados como medidas de avaliação e comparação da qualidade de diferentes alimentos e dietas.

Diante do exposto, o presente estudo objetivou avaliar o teor de lipídeos, colesterol e o perfil de ácidos graxos no músculo Longissimus dorsi de cordeiros Santa Inês alimentados com rações contendo diferentes níveis de energia metabolizável.

\section{Material e Métodos}

O experimento foi desenvolvido no Setor de Ovinocaprinocultura do Departamento de Zootecnia da Universidade Federal do Ceará, em Fortaleza, Ceará.

Foram utilizados 20 cordeiros da raça Santa Inês, 
não-castrados, com peso corporal (PC) médio inicial de $13,0 \pm 0,56 \mathrm{~kg}$ e, aproximadamente, 50 dias de idade, confinados em baias individuais com piso de concreto e providas de comedouro e bebedouro. Os animais foram distribuídos em um delineamento em blocos casualizados com quatro tratamentos e cinco repetições, sendo os tratamentos, rações contendo diferentes níveis de energia metabolizável (2,08; 2,28; 2,47 e 2,69 Mcal kg-1 MS) obtidos a partir de diferentes relações volumoso:concentrado $(75,0: 25,0 ; 62,5: 37,5 ; 50,0: 50,0 ; 37,5: 62,5)$. As rações experimentais foram formuladas conforme $o$ NRC (1985), sendo compostas por feno de capim Tifton 85 moído e quatro rações concentradas.

As rações com maiores níveis energéticos foram formuladas para ganho de peso corporal de $200 \mathrm{~g} /$ dia. As rações foram fornecidas à vontade, uma vez ao dia, às $07 \mathrm{~h}$ da manhã, e ajustadas de forma a permitir sobras em torno de $20 \%$ do fornecido, com água permanentemente à disposição dos animais. A quantidade de ração oferecida foi registrada diariamente e, semanalmente, foram coletadas amostras dos concentrados, feno e das sobras por animal para mensuração do consumo de nutrientes, as quais no final do período experimental formaram uma amostra composta/tratamento/animal.

A duração do experimento foi definida pelo tempo necessário para que a média do peso de todos os animais de cada tratamento alcançasse $28 \mathrm{~kg}$ de peso corporal, ocasião em que os mesmos foram abatidos. O tempo de permanência dos animais no confinamento (119, 96 e 69 dias) decresceu à medida que foi ofertada maior quantidade de concentrado na dieta, antecipando o peso de abate em 50 dias quando se obtém a diferença entre o número de dias de confinamento dos animais recebendo 2,08 e 2,69 Mcal $/ \mathrm{kg}$ de MS, respectivamente. À medida que os animais de cada tratamento foram abatidos, escolhia-se aleatoriamente um animal que estava recebendo a ração com 2,08 Mcal de EM/kg de MS (animal referência), para ser abatido.

Os animais foram pesados ao início do experimento e a cada sete dias, durante o período experimental. Os animais foram abatidos após jejum de 18 horas de alimento sólido e liquido. Após o abate, as carcaças foram acondicionadas em sacos plásticos devidamente identificados e alocadas em câmara frigorífica a $4^{\circ} \mathrm{C}$ por 24 horas. Decorrido esse tempo, as carcaças foram novamente pesadas para obtenção do peso da carcaça fria $(\mathrm{PCF})$ e, em seguida seccionadas longitudinalmente e, na meia carcaça esquerda, foi efetuado um corte transversal, na altura da $12^{\mathrm{a}}$ e $13^{\mathrm{a}}$ costela, para obtenção do músculo Longissimus dorsi conforme metodologia descrita por Cezar e Sousa (2007).

Após a retirada da gordura de cobertura, as amostras do músculo Longissimus dorsi foram embaladas em sacos de polietileno, identificadas e congeladas. No momento das análises, as mesmas foram lentamente descongeladas em refrigeração e após serem trituradas e homogeneizadas, foram retiradas $10 \mathrm{~g}$ para análise de colesterol e, $5 \mathrm{~g}$ para análise do perfil de ácidos graxos.

Para a determinação de lipídeos totais e colesterol, o extrato lipídico foi obtido segundo a técnica de extração descrito por Folch, Less e Stanley (1957). Após determinação dos lipídeos totais, o material extraído foi utilizado para a determinação do colesterol segundo Searcy e Bergquist (1960). O extrato lipídico para determinação do perfil de ácidos graxos foi obtido por meio da técnica descrita por Bligh e Dyer (1959). Sequencialmente, a leitura dos ésteres de ácidos graxos foi realizada por meio de cromatografia gasosa de acordo com Precht e Molkentin (1996). A partir do perfil dos ácidos graxos identificados foi calculado o somatório dos ácidos graxos saturados (AGS), ácidos graxos insaturados (AGI), ácidos graxos desejáveis (AGD) $(\mathrm{AGD}=\mathrm{AGMI}+\mathrm{AGPI}+\mathrm{C} 18: 0)$ e definidas as relações AGPI:AGS, AGPI:AGM, AGM:AGS,

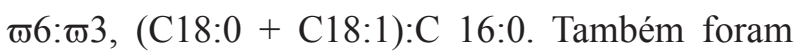
calculados os índices de Aterogenicidade $(\mathrm{IA}=$ [ $(\mathrm{C} 12: 0+(4 \times \mathrm{C} 14: 0)+\mathrm{C} 16: 0)] /(\Sigma \mathrm{AGMI}+\Sigma \varpi 6$ $+\Sigma \varpi 3)$; Índice de Trombogenicidade (IT) $=(\mathrm{C} 14: 0$ $+\mathrm{C} 16: 0+\mathrm{C} 18: 0) /[(0,5 \mathrm{X} \Sigma \mathrm{AGMI})+(0,5 \mathrm{X} \Sigma \varpi 6$ 
$\left.+(3 \mathrm{X} \Sigma \varpi 3)+\left(\sum \varpi 3 / \sum \varpi 6\right)\right]$, segundo Ulbricht e Southgate (1991) e a razão entre ácidos graxos hipocolesterolêmicos e hipercolesterolêmicos $(\mathrm{h}: \mathrm{H}=$

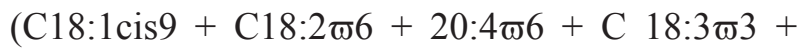
$\mathrm{C} 20: 5 \varpi 3+\mathrm{C} 22: 5 \varpi 3+\mathrm{C} 22: 6 \varpi 3) /(\mathrm{C} 14: 0+\mathrm{C} 16: 0)$, segundo Santos-Silva, Bessa e Mendes (2002). Esses parâmetros foram utilizados para a determinação da qualidade nutricional da fração lipídica do músculo Longissimus dorsi dos cordeiros Santa Inês.

Os ingredientes, rações concentradas e feno foram submetidos às análises de matéria seca (MS), matéria mineral (MM), proteína bruta (PB) e extrato etéreo (EE), conforme os procedimentos recomendados por Silva e Queiroz (2002). As análises de fibra em detergente neutro (FDN) e fibra em detergente ácido (FDA) foram realizadas, segundo Van Soest, Robertson e Lewis (1991). O teor de carboidratos totais (CT) foi calculado utilizando a expressão: CT $(\%)=100-(\% \mathrm{~PB}+\% \mathrm{EE}+\% \mathrm{MM})$, segundo Sniffen et al. (1992). Os carboidratos não-fibrosos (CNF) foram calculados a partir de equação adaptada de Weiss (1999), onde: CNF (\%) $=100-(\%$ FDNcp $+\%$ PB $+\%$ EE $+\%$ MM $)$. Para os concentrados, devido à presença de ureia em sua constituição, o teor de CNF foi calculado conforme adaptação da equação proposta por Hall (2000), sendo $\mathrm{CNF}=100-[(\% \mathrm{~PB}-\% \mathrm{~PB}$ derivado da ureia $+\%$ da ureia $)+\%$ FDNcp $+\%$ EE $+\%$ cinzas $]$. A composição percentual dos ingredientes e químicobromatológica dos concentrados e do feno, assim como, das rações experimentais, são apresentadas nas Tabelas 1 e 2, respectivamente.

As variáveis experimentais foram submetidas à análise de variância e regressão utilizando o pacote computacional SAS 9.0 (2002).

Tabela 1. Composição bromatológica dos ingredientes em \% MS utilizados e dos concentrados avaliados (\% MS).

\begin{tabular}{lrrrrrrr}
\hline Nutrientes & Feno & Milho & Soja & Conc. 1 & Conc. 2 & Conc. 3 & Conc. 4 \\
\hline Matéria seca & 92,73 & 91,44 & 92,54 & 90,30 & 90,18 & 90,94 & 90,30 \\
Matéria mineral & 6,03 & 1,74 & 6,84 & 3,53 & 3,76 & 3,56 & 3,71 \\
Proteína bruta & 9,94 & 9,39 & 44,05 & 21,14 & 21,72 & 22,00 & 22,27 \\
Extrato etéreo & 0,84 & 5,36 & 4,13 & 3,60 & 4,30 & 5,00 & 4,26 \\
Fibra em detergente neutro & 75,03 & 14,78 & 15,78 & 15,91 & 15,15 & 16,01 & 14,87 \\
Fibra em detergente ácido & 36,32 & 4,78 & 9,24 & 5,63 & 5,67 & 2,70 & 5,83 \\
FDN $_{\text {CP }}{ }_{\text {Carboidratos totais }}^{67,91}$ & 12,76 & 13,74 & 14,16 & 13,72 & 14,61 & 13,45 \\
Carboidratos não-fibrosos & 83,19 & 83,51 & 44,98 & 71,73 & 70,23 & 69,43 & 69,75 \\
\hline
\end{tabular}

* Fibra em detergente neutro corrigido para cinzas e proteína

Fonte: Elaboração dos autores. 
Tabela 2. Composição percentual e bromatológica das rações experimentais.

\begin{tabular}{lrrrr}
\hline \multirow{2}{*}{ Composição percentual (\%MN) } & \multicolumn{3}{c}{ Concentração de EM (Mcal/kg MS) } \\
\cline { 2 - 5 } & $\mathbf{2 , 0 8}$ & $\mathbf{2 , 2 8}$ & $\mathbf{2 , 4 7}$ & $\mathbf{2 , 6 9}$ \\
\hline Feno de Tifton & 75,00 & 62,50 & 50,00 & 37,50 \\
Concentrado & 25,00 & 37,50 & 50,00 & 62,50 \\
$\quad$ Fubá de milho & 77,90 & 77,60 & 77,40 & 77,39 \\
$\quad$ Farelo de soja & 20,00 & 20,00 & 20,20 & 20,00 \\
$\quad$ Ureia & 0,88 & 1,18 & 1,22 & 1,25 \\
$\quad$ Calcário & 0,00 & 0,26 & 0,31 & 0,62 \\
$\quad$ Fosfato bicálcico & 0,26 & 0,26 & 0,26 & 0,26 \\
$\quad$ Cloreto de sódio & 0,88 & 0,62 & 0,44 & 0,35 \\
$\quad$ Premix mineral ${ }^{1}$ & 0,06 & 0,04 & 0,13 & 0,13 \\
\hline Composição bromatológica (\%MS) & & & & \\
\hline Matéria seca & 92,12 & 91,77 & 91,83 & 91,21 \\
Matéria mineral & 5,40 & 5,18 & 4,80 & 4,58 \\
Proteína bruta & 12,74 & 14,36 & 15,97 & 17,65 \\
Extrato etéreo $_{\text {Fibra em detergente neutro }}$ & 1,53 & 2,13 & 2,92 & 2,98 \\
Fibra em detergente ácido & 60,25 & 52,57 & 45,52 & 37,43 \\
FDN & 28,64 & 24,82 & 19,51 & 17,26 \\
Carboidratos totais & 54,47 & 47,59 & 41,26 & 33,87 \\
Carboidratos não-fibrosos $_{\text {Nutrientes digestíveis totais }}$ & 80,33 & 78,33 & 76,31 & 74,79 \\
\hline
\end{tabular}

${ }^{1}$ Composição: Ca 7,5\%; P 3\%; Fe 16.500 ppm, Mn 9.750 ppm, Zn 35.000 ppm, I 1.000 ppm, Se 225 ppm, Co 1.000 ppm

Fonte: Elaboração dos autores.

\section{Resultados e Discussão}

Foi detectado efeito $(\mathrm{P}<0,05)$ dos níveis de energia metabolizável $(\mathrm{EM})$ sobre o consumo de matéria seca, expresso em $\mathrm{g} / \mathrm{dia}$ e $\mathrm{g} / \mathrm{kg}^{0,75}$, apresentando efeito linear crescente (Tabela 3). Contudo, para o consumo de $\mathrm{MS}$, expresso em \% $\mathrm{PV}$, não foi observada influência dos níveis de energia nas rações, registrando-se consumo médio de 4,41\% PV. Resultados semelhantes foram obtidos por Alves et al. (2003) estudando três níveis de EM (2,42; 2,66 e 2,83 Mcal de EM/kg de MS), utilizando feno de Tifton 85 e ração concentrada a base de milho grão moído e farelo de soja, para ovinos Santa Inês. As bases para expressão de consumo são diferentes para os mecanismos físicos e fisiológicos de controle. Para rações de baixa qualidade, em que ingestão é limitada pelo enchimento do rúmen (mecanismo físico de controle), é adequado expressá-lo em $\% \mathrm{PV}$, por se encontrar mais relacionado ao tamanho e a capacidade do trato digestório. Quando a densidade energética da ração é elevada, em relação às exigências do animal, o consumo é limitado pela demanda energética, não ocorrendo repleção ruminal, e a melhor forma de expressá-lo é com base no peso metabólico $\left(\mathrm{g} / \mathrm{kg}^{0,75}\right)$. 
Tabela 3. Consumo de nutrientes, coeficiente de variação (CV) e coeficiente de determinação (R2) em ovinos Santa Inês alimentados com diferentes níveis de energia metabolizável (EM).

\begin{tabular}{|c|c|c|c|c|c|c|}
\hline \multirow{2}{*}{ Variáveis } & \multicolumn{4}{|c|}{ Níveis de EM (Mcal/kg MS) } & \multirow{2}{*}{$\mathbf{R}^{2}$} & \multirow{2}{*}{$\mathrm{CV} \%$} \\
\hline & 2,08 & 2,28 & 2,47 & 2,69 & & \\
\hline \multicolumn{7}{|c|}{ Consumo (g/dia) } \\
\hline Matéria seca $^{1}$ & 695,02 & 914,17 & 1030,16 & 1287,06 & 0,98 & 27,65 \\
\hline Proteína bruta² & 107,58 & 172,19 & 205,81 & 253,64 & 0,97 & 28,73 \\
\hline Extrato etéreo $^{3}$ & 11,80 & 21,49 & 34,96 & 40,28 & 0,98 & 30,81 \\
\hline Fibra em detergente neutro ${ }^{4}$ & 382,24 & 443,38 & 422,54 & 406,89 & - & 27,90 \\
\hline \multicolumn{7}{|c|}{ Consumo (\%PV) } \\
\hline Matéria seca ${ }^{5}$ & 4,01 & 4,36 & 4,53 & 4,68 & - & 18,25 \\
\hline Fibra em detergente neutro ${ }^{6}$ & 2,21 & 2,12 & 1,84 & 1,48 & 0,93 & 18,48 \\
\hline \multicolumn{7}{|c|}{ Consumo $\left(\mathrm{g} / \mathrm{kg}^{0,75}\right)$} \\
\hline Matéria seca ${ }^{7}$ & 80,54 & 93,27 & 98,70 & 107,02 & 0,97 & 18,99 \\
\hline Fibra em detergente neutro ${ }^{8}$ & 44,40 & 45,27 & 40,27 & 33,77 & 0,89 & 18,95 \\
\hline
\end{tabular}

NS = Não significativo

${ }^{1} \hat{Y}=-1249,47+937,54 \mathrm{EM}(\mathrm{P}=0,002)$

${ }^{2} \hat{\mathrm{Y}}=-1378,86+1008,10 \mathrm{EM}(\mathrm{P}=0,01)$

${ }^{3} \hat{Y}=-88,13+48,45 \mathrm{EM}(\mathrm{P}=0,0001)$

${ }^{4} \tilde{Y}=413,76^{\mathrm{NS}}$

${ }^{5} \tilde{Y}=4,39$ NS

${ }^{6} \hat{\mathrm{Y}}=4,91-1,25 \mathrm{EM}(\mathrm{P}=0,0004)$

${ }^{7} \hat{\mathrm{Y}}=-3,48+41,37 \mathrm{EM}(\mathrm{P}=0,02$

${ }^{8} \hat{\mathrm{Y}}=86,44-19,07 \mathrm{EM}(\mathrm{P}=0,009)$

Fonte: Elaboração dos autores.

Para rações de densidade energética baixa, o consumo será limitado pelo enchimento do rúmenretículo. De fato, o consumo de FDN (\%PV e g/ $\mathrm{kg}^{0,75}$ ) foi influenciado, apresentando comportamento linear decrescente $(\mathrm{P}<0,05)$ com o aumento dos níveis de energia nas rações, promovendo maior consumo de MS, indicando que as exigências energéticas dos animais, provavelmente, tenham sido atingidas com níveis mais altos de consumo. O consumo de $\mathrm{PB}$ e EE, expressos em g/dia, apresentaram comportamento semelhante ao consumo de MS, registrando-se efeito linear crescente $(\mathrm{P}<0,05)$ o que pode ser justificado pela maior concentração destes nutrientes nas rações, conforme pode ser observado na Tabela 2.

A análise do perfil lipídico do músculo Longissimus dorsi indicou efeito linear crescente e decrescente para os ácidos Cis-10 heptadecanóico (C17:1) e eicosatrienóico (C20:3), respectivamente, com o aumento nos níveis de energia dietéticos (Tabela 4). Contudo, para os demais ácidos graxos saturados, bem como para os monoinsaturados e poliinsaturados não foram observadas diferenças significativas $(\mathrm{P}>0,05)$. A composição dos lipídeos dietéticos é refletida no perfil da gordura da carcaça na maioria das espécies, contudo para os ruminantes os lipídeos dietéticos são amplamente modificados pelos microrganismos do rúmen, principalmente, no que se refere aos ácidos graxos poliinsaturados, apresentando efeitos sobre o conteúdo e composição dos ácidos graxos no músculo esquelético.

Os ácidos palmítico (C16:0) e esteárico (C18:0) contribuíram mais intensamente nos valores totais de ácidos graxos saturados, o que está de acordo com os relatos de Ferrão et al. (2009) ao avaliarem diferentes relações volumoso:concentrado (100:0; $75: 25$ e 50:50) na dieta de cordeiros Santa Inês. O total de ácidos graxos monoinsaturados não foi 
influenciado pelos níveis energéticos das rações, apresentado valor numérico médio de 42,32\%. Embora não tenham sido observadas variações significativas no perfil do ácido graxo oléico com o incremento de energia na ração, destaca-se que, cerca de $95 \%$ dos ácidos graxos monoinsaturados presentes no Longissimus dorsi dos cordeiros Santa Inês foram representados por esse ácido graxo. Resultados semelhantes foram relatados por Banskalieva, Sahlu e Goetsch (2000) e Sañudo et al. (2000) para caprinos e ovinos, respectivamente.

Tabela 4. Perfil de ácidos graxos do Longissimus dorsi, coeficiente de variação (CV) e coeficiente de determinação (R2) em ovinos Santa Inês alimentados com diferentes níveis de energia metabolizável (EM).

\begin{tabular}{|c|c|c|c|c|c|c|c|}
\hline \multirow{2}{*}{ Ácido Graxo } & \multirow{2}{*}{ Denominação } & \multicolumn{4}{|c|}{ Níveis de EM (Mcal/kg MS) } & \multirow{2}{*}{$\mathbf{R}^{2}$} & \multirow{2}{*}{ CV } \\
\hline & & 2,08 & 2,28 & 2,47 & 2,69 & & \\
\hline Saturados $^{1}$ & & 45,44 & 43,7 & 42,07 & 43,41 & - & 12,74 \\
\hline $\mathrm{C} 10: 0^{2}$ & Cáprico & 0,14 & 0,42 & 0,24 & 0,28 & - & 140,12 \\
\hline $\mathrm{C} 14: 0^{3}$ & Mirístico & 1,47 & 0,78 & 1,86 & 1,87 & - & 23,14 \\
\hline $\mathrm{C} 16: 0^{4}$ & Palmítico & 22,76 & 20,73 & 22,97 & 22,48 & - & 5,46 \\
\hline $\mathrm{C} 17: 0^{5}$ & Heptadecanóico & 1,30 & 1,11 & 1,53 & 1,39 & - & 37,12 \\
\hline $\mathrm{C} 18: 0^{6}$ & Esteárico & 19,91 & 20,66 & 15,47 & 17,39 & - & 34,60 \\
\hline Monoinsaturados ${ }^{7}$ & & 41,2 & 35,32 & 47,52 & 45,25 & - & 23,69 \\
\hline $\mathrm{C} 16: 1^{8}$ & Palmitoléico & 1,30 & 1,11 & 1,53 & 1,39 & - & 28,01 \\
\hline $\mathrm{C} 17: 1^{9}$ & Cis-10 Heptadecanóico & 0,68 & 0,51 & 1,08 & 1,22 & 0,72 & 45,02 \\
\hline $\mathrm{C} 18: \ln 9 \mathrm{c}^{10}$ & Oléico e isômero & 39,22 & 33,7 & 44,91 & 42,64 & - & 24,61 \\
\hline Poliinsaturados ${ }^{11}$ & & 6,26 & 10,6 & 3,55 & 2,82 & - & 69,23 \\
\hline $\mathrm{C} 18: 2 \mathrm{n} 6 \mathrm{c}^{12}$ & Linoléico & 3,56 & 6,79 & 2,40 & 1,99 & - & 60,95 \\
\hline $\mathrm{C} 20: 3 \mathrm{n} 3^{13}$ & Eicosatrienóico & 2,70 & 3,81 & 1,15 & 0,83 & 0,62 & 84,97 \\
\hline Insaturados ${ }^{14}$ & & 47,46 & 45,92 & 51,07 & 48,07 & - & 21,34 \\
\hline
\end{tabular}

$\mathrm{NS}=$ Não significativo

${ }^{1} \tilde{Y}=43,65^{\mathrm{NS}}$

${ }^{2} \tilde{Y}=0,27^{\mathrm{NS}}$

${ }^{3} \tilde{Y}=1,49^{\mathrm{NS}}$

${ }^{4} \tilde{Y}=22,23$ NS

${ }^{5} \tilde{Y}=1,33^{\mathrm{NS}}$

${ }^{6} \tilde{Y}=18,36{ }^{\mathrm{NS}}$

${ }^{7} \tilde{Y}=42,32$ NS

${ }^{8} \tilde{Y}=1,33^{\mathrm{NS}}$

${ }^{9} \hat{Y}=-1,49+1,00$ EM $(\mathrm{P}=0,022)$

${ }^{10} \tilde{Y}=40,11^{\mathrm{NS}}$

${ }^{11} \tilde{Y}=5,87^{\mathrm{NS}}$

${ }^{12} \tilde{Y}=5,87^{\mathrm{NS}}$

${ }^{13} \hat{\mathrm{Y}}=11,15-3,81 \mathrm{EM}(\mathrm{P}=0,42)$

${ }^{14} \tilde{Y}=48,13^{\mathrm{NS}}$

Fonte: Elaboração dos autores.

As concentrações de CLA foram próximas a zero o que não permitiu a realização de análises estatísticas. Provavelmente, o ácido graxo linoléico proveniente dos ingredientes das rações experimentais apresentaram maior acessibilidade aos microrganismos do rúmen, adicionalmente ao ambiente ruminal $(\mathrm{pH})$ e espécies microbianas presentes. A concentração de CLA nos tecidos reflete a quantidade que estaria disponível para absorção no intestino delgado. Esta concentração é influenciada pela manipulação e quantidade de lipídeo presente na dieta. Os ácidos graxos oléico (C18:1), palmítico (C16:0) e esteárico (C18:0) foram, respectivamente, encontrados em maiores concentrações nas amostras do músculo Longissimus dorsi, perfazendo, aproximadamente, $80 \%$ dos ácidos graxos identificados. 
As proporções de tecido muscular e gorduroso dependem da eficiência de utilização dos nutrientes da dieta (ATTI; ROUISSI; MAHOUACHI, 2004). $\mathrm{O}$ excesso de energia nas rações dos ruminantes é metabolizado e armazenado na forma de tecido adiposo, proporcionando maior teor de lipídeo na carcaça. As enzimas responsáveis pela síntese de ácidos graxos, lipogênese e hipertrofia de adipócito, são reguladas pelos produtos finais da fermentação ruminal os quais são determinados pelos componentes dietéticos; em ruminantes, o acetato é o principal precursor na síntese de ácidos graxos na carcaça.

Os ácidos graxos C16:0; C16:1; C18:0; C18:1 e C18:2 constituíram mais de $90 \%$ das áreas totais do cromatograma (Tabela 4). O ácido oléico (C18:1) e isômero foram os ácidos graxos insaturados que mais contribuiram para o perfil dos ácidos graxos, sendo este reconhecidamente apontado como redutor de colesterol e lipoproteínas de baixa densidade (LDL). O ácido graxo esteárico, diferentemente dos outros ácidos graxos saturados, atua na redução do colesterol sérico em humanos, e contrariamente, o ácido graxo palmítico é apontado por aumentar a síntese de colesterol, o que representa um fator de risco para o aparecimento de doenças cardiovasculares (MOLONEY et al., 2001).

Os níveis de colesterol (mg/100g) decresceram em relação ao aumento nos níveis de energia das rações (Tabela 5). Chizzolini et al. (1999), revisando os níveis de colesterol em tecidos de diferentes animais, descreveram um nível de colesterol médio de $45 \mathrm{mg} / 100 \mathrm{~g}$ de Longissimus dorsi de suínos, 43 e $61 \mathrm{mg} / 100 \mathrm{~g}$ de peito de frango com e sem pele, respectivamente, 84 e $85 \mathrm{mg} / 100 \mathrm{~g}$ de sobre coxa de frango com e sem pele, respectivamente, 44 e $51 \mathrm{mg} / 100 \mathrm{~g}$ de peito de peru com e sem pele, respectivamente. Assim, o conteúdo de colesterol encontrado para o músculo Longissimus dorsi de cordeiros Santa Inês (entre 21,74 e 54,06 mg/100 $\mathrm{g}$ do músculo) foram próximas às carnes magras de peito de peru e de frango (sem pele) descritas anteriormente. Os tecidos de animais ruminantes, quando comparados aos dos não ruminantes apresentam maior concentração de ácidos graxos saturados e menor relação poliinsaturados:saturados, sendo esta diferença oriunda do processo de biohidrogenação dos ácidos graxos insaturados pela ação da microbiota ruminal (FRENCH et al., 2000). Salienta-se que vários fatores podem influenciar o processo de biohidrogenação e a composição dos ácidos graxos depositados na carne, bem como seu teor de colesterol. Assim, destacam-se o plano alimentar, a composição das dietas, relação volumoso:concentrado e o tipo de volumoso utilizado (DEMIREL et al., 2006; NUERNBERG et al., 2008). Do ponto de vista prático, os resultados apresentados poderão subsidiar a produção de carne ovina no que se refere aos aspectos qualitativos, podendo contribuir para orientação da produção de um produto que atenda à demanda do mercado consumidor, principalmente relacionado às proporções de músculo e gordura e ao teor de colesterol das carcaças de cordeiros terminados em confinamento.

Não foi observada influência das rações experimentais nas relações de AGPI: AGS; AGPI:AGM; AGM:AGS; h:H; $\omega 6: \omega 3$ e (C18:0 + C18:1): C16:0, bem como, para o teor de AGD, IA e IT, como pode ser observado ainda na Tabela 5 $(\mathrm{P}>0,05)$. As relações ou proporções entre ácidos graxos têm sido estudadas de forma a avaliar e identificar o fator de risco dos alimentos em relação ao aumento do nível de colesterol sanguíneo em humanos. O efeito biológico dos ácidos graxos essenciais depende da relação entre AGPI:AGS, AGPI:AGM e da razão entre os AGM:AGS (MARQUES et al., 2007). Essa relação auxilia na determinação dos fatores de risco dos alimentos. Vale ressaltar que esse índice é correlacionado com a relação $\omega 6: \omega 3$, assim, os valores decrescentes nos níveis do ácido linoléico aumentam os níveis de $\omega 3$ na relação. Observaram-se médias dessa relação que variaram de 1,51 a 3,13 ficando dentro dos limites estabelecidos pela literatura especializada (WOOD et al., 2003; INSAUSTI et al., 2005). 
Tabela 5. Relações dos ácidos graxos saturados (AGS), monoinsaturados (AGM) e poliinsaturados (AGP), coeficiente de determinação $\left(\mathrm{R}^{2}\right)$ e coeficiente de variação $(\mathrm{CV})$ em ovinos Santa Inês alimentados com diferentes níveis de energia metabolizável.

\begin{tabular}{lrrrrrr}
\hline \multirow{2}{*}{ Ácidos Graxos } & \multicolumn{3}{c}{ Níveis de Energia Metabolizável } & \multirow{2}{*}{ (Mcal/kg MS) } & \multirow{2}{*}{ CV (\%) } \\
\cline { 2 - 5 } & $\mathbf{2 , 0 8}$ & $\mathbf{2 , 2 8}$ & $\mathbf{2 , 4 7}$ & $\mathbf{2 , 6 9}$ & & \\
\hline Colesterol (mg/100g) & 54,06 & 49,77 & 24,61 & 21,74 & 0,86 & 34,21 \\
AGPI:AGS $^{2}$ & 0,13 & 0,25 & 0,086 & 0,062 & - & 83,01 \\
AGPI:AGM $^{3}$ & 0,14 & 0,23 & 0,074 & 0,066 & - & 69,33 \\
AGM:AGS $^{4}$ & 0,89 & 0,84 & 1,14 & 1,04 & - & 28,94 \\
$\omega 6: \omega 3^{5}$ & 1,79 & 1,51 & 2,34 & 3,13 & - & 42,80 \\
$\mathrm{AGD}^{6}$ & 67,44 & 66,03 & 66,56 & 65,39 & - & 16,24 \\
IA $^{7}$ & 0,64 & 0,67 & 0,60 & 0,63 & - & 43,41 \\
IT $^{8}$ & 1,31 & 1,38 & 1,31 & 1,46 & - & 36,05 \\
h:H $^{9}$ & 1,89 & 2,28 & 1,92 & 1,84 & - & 8,54 \\
$(\mathrm{C} 18: 0+\mathrm{C} 18: 1): \mathrm{C} 16: 0^{10}$ & 2,62 & 2,65 & 2,65 & 2,67 & - & 23,56 \\
\hline
\end{tabular}

$\mathrm{NS}=$ Não significativo

${ }^{1} \mathrm{Y}=182,75-60,93 \mathrm{EM}(\mathrm{P}=0,008) ;{ }^{2} \tilde{Y}=0,13^{\mathrm{Ns}} ;{ }^{3} \tilde{\mathrm{Y}}=0,12^{\text {Ns; }} ;{ }^{4} \tilde{\mathrm{Y}}=0,97^{\mathrm{Ns}} ;{ }^{5} \tilde{\mathrm{Y}}=2,19^{\mathrm{NS}}$

${ }^{6}$ Ácidos Graxos Desejáveis $=\mathrm{AGM}+\mathrm{AGP}+\mathrm{C} 18: 0 ; \tilde{\mathrm{Y}}=66,3^{\mathrm{NS}}$

7'́ndice de Aterogenicidade $=[(\mathrm{C} 12: 0+(4 * \mathrm{C} 14: 0)+\mathrm{C} 16: 0)] \Sigma$ Insaturados; $\tilde{\mathrm{Y}}=0,63 \mathrm{Ns}$

${ }^{8}$ Índice de trombogenicidade $=\left[\left((\mathrm{C} 14+\mathrm{C} 16+\mathrm{C} 18) /(0,5 * \Sigma \mathrm{AGM})+(3 * \omega 6)+(\omega 6 / \omega 3) ; \tilde{\mathrm{Y}}=1,36^{\mathrm{NS}}\right.\right.$

${ }^{9}$ Razão entre ácidos graxos hipocolesterolêmicos e hipercolesterolêmicos $=(\mathrm{C} 18: 1 \operatorname{cis} 9+\mathrm{C} 18: 2 \omega 6) /(\mathrm{C} 14: 0+16: 0) ; \tilde{Y}=1,98^{\mathrm{NS}}$ ${ }^{10} \tilde{Y}=2,64^{\mathrm{NS}}$

Fonte: Elaboração dos autores.

A concentração de ácidos graxos desejáveis (AGD) é expressa pela somatória dos AGI com o ácido esteárico (BANSKALIEVA; SAHLU; GOETSCH, 2000). Embora o ácido esteárico (C18:0) seja saturado seu efeito é neutro, tendo menos implicações no perfil lipídico, uma vez que pode ser convertido a oléico (C18:1) no organismo. Já os ácidos monoinsaturados, oléico, e os poliinsaturados, linolênico e $\alpha$-linolênico, reduzem os níveis de LDL-colesterol e, consequentemente, o risco de obesidade, câncer e doenças cardiovasculares em humanos (PEREZ et al., 2002). O valor médio encontrado para os IA e IT foram de 0,60 a 0,67 e 1,31 a 1,46, respectivamente. Esses índices relacionam os ácidos pró e antiaterogênicos e indicam o potencial de estímulo a agregação plaquetária, ou seja, quanto menores os valores de IA e IT, maior a quantidade de ácidos graxos antiaterogênicos presentes nas gorduras e, consequentemente, maior o potencial de prevenção ao aparecimento de doenças coronárias.
A relação h:H (hipocolesterolêmicos:hipercoles terolêmicos) é baseada nos efeitos funcionais dos ácidos graxos sobre o metabolismo do colesterol, contudo permite uma melhor avaliação nutricional, além de considerar os efeitos benéficos dos ácidos graxos monoinsaturados nessa relação. O ácido esteárico (C18:0) apesar de ser um ácido saturado não incrementa o colesterol sanguíneo. A média dos resultados encontrados para essa relação no presente trabalho $(1,98)$ foram inferiores aquelas mencionadas por Santos-Silva, Bessa e Mendes (2002) para o Longissimus thoracis de cordeiros $(2,11)$. Quanto à relação $(\mathrm{C} 18: 0+\mathrm{C} 18: 1): \mathrm{C} 16: 0$, a variação observada foi de 2,62 a 2,67. Costa et al. (2009) relataram média inferior de 2,20 em cordeiros alimentados com dois níveis de energia metabolizável (2,5 e 3,0 Mcal/ Kg de MS). Banskalieva, Sahlu e Goetsch (2000) destacaram que a relação (C18:0 + C18:1): C16:0 descreve possíveis efeitos benéficos dos diferentes lipídios encontrados nos alimentos, com valores de 2,1 a $2,8 \%$ para ovinos. 


\section{Conclusão}

Os níveis de energia dietéticos influenciam os lipídeos totais, teor de colesterol, e o teor do ácido graxo saturado cis 10-heptadecanóico, bem como do ácido graxo poliinsaturado eicosatrienóico no músculo Longissimus dorsi de cordeiros da raça Santa Inês.

\section{Referências}

ALVES, K. S.; CARVALHO, F. F. R.; FERREIRA, M. A.; VÉRAS, A. S. C.; ANDRADE, M. F.; COSTA, R. G.; BATISTA, A. M. V.; MEDEIROS, A. N.; MAIOR JUNIOR, R. J. S.; ANDRADE, D. K. B. Níveis de energia em dietas de ovinos Santa Inês: características de carcaça e constituintes corporais. Revista Brasileira de Zootecnia, Viçosa, MG, v. 32, n. 6, p. 1927-1936, 2003. Suplemento 2 .

ANDRAE, J. G.; DUCKETT, S. K.; HUNT, C. W.; PRITCHARD, G. T.; OWENS, F. N. Effects of feeding high-oil corn to beef steers on carcass characteristics and meat quality. Journal of Animal Science, Savoy, v. 79, n. 3, p. 582-588, 2001.

ATTI, N.; ROUISSI, H.; MAHOUACHI, M. The effect of dietary crude protein level on growth, carcass and meat composition of male goat kids in Tunisia. Small Ruminant Research, Amsterdam, v. 54, n. 1-2, p. 89-97, 2004.

BANSKALIEVA, V.; SAHLU, T.; GOETSCH, A. L. Fatty acid composition of goat muscles and fat depots: a review. Small Ruminant Research, Amsterdam, v. 37, n. 3, p. 255-268, 2000.

BLIGH, E. G.; DYER, W. J. A rapid method of total lipid extraction and purification. Canadian journal of Biochemistry and Physiology, Birmingham, v. 37, n. 8, p. 911-917, 1959.

CEZAR, M. F.; SOUZA,W. H. Carcaças ovinas e caprinas, obtenção, avaliação, classificação. João Pessoa: Agropecuária Tropical, 2007. 147 p.

CHIZZOLINI, R.; ZANARDI, E.; DORIGONI, V.; GHIDINI, S. Calorific value and cholesterol content of normal and low-fat meat and meat products. Trends in food science Technology, Cambridge, v. 10, n. 1, p. 119128, 1999.

COSTA, R. G.; BATISTA, A. S. M.; AZEVEDO, P. S. A.; QUEIROGA, R. C. R. E.; MADRUGA, M. S.; ARAÚJO FILHO, J. T. Lipid profile of lamb meat from different genotypes submitted to diets with different energy levels. Revista Brasileira de Zootecnia, Viçosa, v. 38, n. 3, p. 532-538, 2009.

DEMIREL, G.; OZPINAR, H.; NAZLI, B., KESER, O. Fatty acids of lamb meat from two breeds fed different forage: concentrate ratio. Meat Science, Amsterdam, v. 72, n. 2, p. 229-235, 2006

FERRÃO, S. P. B.; BRESSAN, M. C.; OLIVEIRA, R. P.; PÉREZ, J. R. O.; RODRIGUES, E. C.; NOGUEIRA, D. A. Características sensoriais da carne de cordeiros da raça Santa Inês submetidos a diferentes dietas. Ciência e Agrotecnologia, Lavras, v. 33, n. 1, p. 185-190, 2009.

FOLCH, J.; LESS, M.; STANLEY, S. A simple method for the isolation and purification of total lipids from animal tissues. Journal of Biological Chemistry, Bethesda, v. 226, n. 1, p. 497-509, 1957.

FRENCH, P.; STANTON, C.; LAWLESS, F.; O'RIORDAN, E. G.; MONAHAN, F. J.; CAFFREY, P. J.; MOLONEY, A. P. Fatty acid composition, including conjugated linoleic acid of intramuscular fat from steers offered grazed grass, grass silage, or concentrate-based diets. Journal of Animal Science, Savoy, v. 78, n. 11, p. 2849-2855, 2000.

HALL, M. B. Calculation of non-structural carbohydrate content of feeds that contain non-protein nitrogen. Gainesville: University of Florida, 2000. 25 p. (Bulletin, 339).

INSAUSTI，K.; GOÑI，V.; GORRAIZ， E. P. C.; BERIAIN, M. J. Effect of weight at slaughter on the volatile compounds of cooked beef from Spanish cattle breeds. Meat Science, Amsterdam, v. 70, n. 1, p. 83-90, 2005.

MARQUES, A. V. M. S.; COSTA, R. G.; SILVA, A. M. A.; PEREIRA FILHO, J. M.; MADRUGA, M. S.; LIRA FILHO, G. E. Rendimento, composição tecidual e musculosidade da carcaça de cordeiros Santa Inês alimentados com diferentes níveis de feno de flor-deseda na dieta. Revista Brasileira de Zootecnia, Viçosa, MG, v. 36, n. 3, p. 610-617, 2007.

MOLONEY, A. P.; MOONEY, M. T.; KERRY, J. P.; TROY, D. J. Producing tender and flavor some beef with enhanced nutritional characteristics. Proceedings of the Nutrition Society, v. 60, n. 5, p. 221-229, 2001.

NATIONAL RESEARCH COUNCIL - NRC. Nutrient requirements of sheep. Washington DC, 1985. $99 \mathrm{p}$.

NUERNBERG, K.; FISCHER, A.; NUERNBER, G. G.; ENDER, K.; DANNENBERGER, D. Meat quality and fatty acid composition of lipids in muscle and fatty tissue of Skudde lambs fed grass versus concentrate. Small Ruminant Research, v. 74, n. 1-3, p. 279-283, 2008. 
PARODI, P. W. Conjugated linoleic acid and other anticarcinogenic agents of bovine milk fat. Journal of Dairy Science, Savoy, v. 82, n. 6, p. 1339-1349, 1999.

PEREZ, J. R. O.; BRESSAN, M. C.; BRAGAGNOLO, N.; PRADO, O. V.; LEMOS, A. L. S. C.; BONAGURIO, S. Efeito do peso ao abate de cordeiros Santa Inês e Bergamácia sobre o perfil de ácidos graxos, colesterol e propriedades químicas. Ciência e Tecnologia de Alimentos, Campinas, v. 22, n. 1, p. 11-18, 2002.

PRECHT, D.; MOLKETIN, J. Rapid analysis of the isomers of trans-octadecenoic acid in milk fat. Internacional Dairy Journal, Edmonton, v. 6, n. 8, p. 791-809, 1996.

SANTOS-SILVA, J.; BESSA, R. J. B.; MENDES, I. A. The effect of genotype, feeding system and slaughter weight on the quality of light lamb. II Fatty acid composition of meat. Livestock Science, v. 77, n. 2, p. 187-194, 2002.

SAÑUDO, C.; ENSER, M. E.; CAMPO, M. M.; NUTE, G. R.; MARÍA, G.; SIERRA, I.; WOOD, J. D. Fatty acid composition and sensory characteristics of lambs carcass from Britain and Spain. Meat Science, Amsterdam, v. 54, n. 4, p. 339-346, 2000.

SEARCY, T. L.; BERGQUIST, L. M. A new colour reaction for the quantification of serum cholesterol. Clinica Chimica Acta, Amsterdam, v. 5, p. 192-199, 1960.
SILVA, D. J.; QUEIROZ, A. C. Análise de alimentos: métodos químicos e biológicos. 3. ed. Viçosa: UFV, 2002. $235 \mathrm{p}$.

SNIFFEN, C. J.; O'CONNOR, D. J.; VAN SOEST, P .J.; SNIFFEN, C. J. A net carbohydrate and protein system for evaluating cattle diets: carbohydrate and protein availability. Journal of Animal Science, Savoy, v. 70, n. 11, p. 3562-3577, 1992.

STATISTICAL ANALYSIS SYSTEM - SAS. SAS Systems for linear models. Cary: SAS Institute, 2002.

ULBRICHT, T. L. V.; SOUTHGATE, D. A. T. Coronary heart disease: seven dietary factors. Lancet, v. 338, n. 8773, p. 985-992, 1991.

VAN SOEST, P. J.; ROBERTSON, J. B.; LEWIS, B. A. Methods for dietary fiber, neutral detergent fiber, and no starch polyssacharides in relation to animal nutrition. Journal of Dairy Science, Savoy, v. 74, n. 10, p. 35833597, 1991.

WEISS, W. P. Energy prediction equations for ruminant feeds. In: CORNELL NUTRITION CONFERENCE FOR FEED MANUFACTURERS, 61., 1999, Ithaca. Proceedings... Ithaca: Cornell University, 1999.

WOOD, J. D.; RICHARDSON, R. L.; NUTE, G. R. FISHER, A. V.; CAMPO, M. M.; KASAPIDOU, E.; SHEARD, P. R.; ENSER, M. Effects of fatty acids on meat quality: a review. Meat Science, Amsterdam, v. 66, n. 1, p. 21-32, 2003. 
